\title{
CURRÍCULO E SALA DE AULA
}

\section{CLASSROOM AND CURRICULUM}

\author{
Wilher de Freitas Guimarães ${ }^{1}$ \\ Edna Gomes Roriz ${ }^{2}$ \\ Rita Amélia Teixeira Vilela ${ }^{3}$
}

\section{RESUMO}

O objetivo da pesquisa foi investigar o currículo materializado na sala de aula de Física, interpretando o que os dados nos revelaram, no processo de didatização do conhecimento, sobre a efetivação das diretrizes curriculares do ensino de Física. A metodologia utilizada foi a Hermenêutica Objetiva, um procedimento de pesquisa empírica qualitativa e interpretativa, que permitiu compreender a escola a partir da reconstituição da aula. A investigação apontou que a disciplina analisada na sala de aula não confirma a realização das diretrizes curriculares de um ensino de Física que promova a autonomia para o aprender a partir dos elementos próximos, práticos e vivenciais dos alunos. Em vários momentos, a aula resulta na semiformação e na falta de um ensino da Física abordado enquanto construção histórica, como atividade social humana na qual as teorias científicas mantêm uma relação complexa com o contexto social, político, econômico e cultural em que ocorreram. Fato que reforça um processo educacional de mitificação do conhecimento científico, por parte dos alunos, e limita a atuação dos mesmos, como cidadãos ativos e críticos, capazes de emitirem juízos de valor em relação a situações sociais que envolvam aspectos físicos e/ou tecnológicos relevantes.

Palavras-chave: Teoria Crítica - Currículo - Sala de Aula - Conhecimento Semiformação.

\section{ABSTRACT}

The goal of the research was to investigate the materialized curriculum in a Physics classroom, interpreting what the data revealed to us, in the process of didatization of knowledge about the effectiveness of the curriculum guidelines of physics teaching. The methodoly used was the Objective Hermeneutics, a procedure of qualitative and interpretative research, developed by the sociologist Ulrich Oevermann, that allowed us to understand the school from the reconstruction of the lesson. The study showed that the subject that was analised in the classroom doesn't confirm the accomplishment of the "diretrizes curriculares" of a Physics teaching that promote the autonomy for the learning from the closer elements, practical and liveable of the students. At many times, the class based on the common sense, in mistaken information and even redutionists, result in the semiformation and in the lack of a Physics teaching approached while historical building, as a social human activity in which the theories keep a complex relation with the social context, politics, economical and cultural that occurred. This fact reinforces an educational process of mitification of scientific knowledge, on the side of the students and limits their 
perfoming as active and critical citizens, capable of making value judgement in relation to social situations that involve physical aspects and / or relevant technological.

Keywords: Critical Theory - Curriculum - Classroom - Knowledge - Semiformation.

\section{INTRODUÇÃO}

Atualmente, as concepções tradicionais que constituíram o núcleo de noções de currículo e conhecimento foram colocadas em xeque pelas teorias críticas do currículo. Sendo assim, o currículo não é um corpo neutro, inocente e desinteressado de conhecimentos, mas envolve a construção de valores e significados culturais. Desse modo, as teorias críticas sobre currículos não aceitam os conhecimentos selecionados e os saberes dominantes, a serem trabalhados na sala de aula, apenas como questões meramente técnicas onde a construção dos conteúdos se concentra, sobremaneira, em exposições didáticas conceituais de fórmulas e leis, desarticuladas e distanciadas do mundo vivido pelos alunos e professores, sem relação com o contexto social em que ocorreram.

De fato, num modelo curricular tradicional, simplista, operacional, técnico e enciclopédico, numa visão tipicamente cartesiana, positivista e mecanicista, onde o conhecimento é seriado, compartimentalizado e somente reproduzido, pelo professor, a possibilidade do exercício da experiência formativa do aluno em conhecer a realidade para transformá-la fica afastada. Nessa perspectiva, o currículo é visto como um processo de racionalização de resultados educacionais, cuidadosa e rigorosamente especificados e medidos, onde os conhecimentos, a serem transmitidos, não são problematizados, porque são apresentados como objetivos e neutros, um resultado da genialidade dos cientistas. Nesse sentido, de acordo com Silva, "o currículo é organizado com vista a conferir-lhe características de ordem, racionalidade e eficiência, já que as finalidades da educação estão dadas pelas exigências profissionais da vida adulta" (SILVA, 1999, p.23). 


\section{EDUCAÇÃO PARA A FORMAÇÃO PLENA DO SUJEITO: FORMAÇÃO (BILDUNG) COMO AUTONOMIA}

No entanto, nos Parâmetros Curriculares Nacionais, o Ensino das Ciências da Natureza e suas Tecnologias, devem envolver na ação docente,

o desenvolvimento de conhecimentos práticos, contextualizados, que respondam às necessidades da vida contemporânea, e o desenvolvimento de conhecimentos mais amplos e abstratos, que correspondam a uma cultura geral e a uma visão de mundo. (...) a crescente valorização do conhecimento e da capacidade de inovar demanda cidadãos capazes de aprender continuamente, para o que é essencial uma formação geral e não apenas um treinamento específico (BRASIL, 1998, p.6).

Podemos notar que essa teorização tem reflexos enormes, na metodologia e no desenvolvimento das Ciências, no contexto da sala de aula. Nessa direção, introduz profundas modificações na abordagem do conhecimento científico, por parte do docente. A premissa é que não basta, apenas ao aluno, ter conhecimento científico sobre a natureza; também é necessário que ele entenda como a ciência funciona, pois só assim as características e os limites deste saber podem ser avaliados.

No caso da educação básica, é essencial, na formação do aluno, uma abordagem e um tratamento do conhecimento científico enquanto construção histórica, como atividade social humana que emerge da cultura, com vista a levar o educando à compreensão de que os,

modelos explicativos não são únicos nem finais, tendo se sucedido ao longo dos tempos (...).O surgimento de teorias físicas mantém uma relação complexa com o contexto social em que ocorreram. Essa percepção do saber físico como construção humana constitui-se condição necessária, mesmo que não suficiente, para que se promova a consciência de uma responsabilidade social e ética. Nesse sentido, deve ser considerado o desenvolvimento da capacidade de se preocupar com o todo social e com a cidadania (BRASIL, 1998, p.27).

Não se pode deixar de mencionar ainda o fato de que o paradigma moderno de conhecimento científico, antes intocável, vem sofrendo mudanças desde o último século pondo fim "às ilusões modernistas e iluministas, que foram, no entanto, incorporadas pela escola" (DOLL, 2002, p. 128). No seguimento desse raciocínio, defende Moreira (2006) que as noções de conhecimento, características das experiências curriculares presentemente propostas aos estudantes estão, 
também, em mais de uma dimensão, em "descompasso com as modificações sociais, com as profundas transformações na natureza e extensão do conhecimento e também nas formas de concebê-lo" (MOREIRA, 2006, p.154). Nessa hipótese de trabalho, a ação docente, juntamente com as suas teorias pedagógicas e curriculares, não pode passar ao largo desta discussão, se almeja a formação (Bildung) do aluno como o cerne do ato educativo. Pois a educação não é uma mera transmissão do saber e não há dúvidas de que é extremamente relevante refletir a respeito da importância de se concretizar na sala de aula e, através dela, na escola, a legitimação de todos os processos que propiciam as condições do desenvolvimento acadêmico, psicológico e emocional do indivíduo, com vista ao desenvolvimento da sua plena autonomia. Nesse contexto, é preciso escapar aos ditames de um formalismo escolar e de um ensino uniformizante que restringe a reflexão sobre a realidade social ao privilegiar a instrução.

Assim, é fundamental que o docente discuta com os seus alunos as condições históricas e filosóficas onde foi possível o desenvolvimento do conhecimento científico da natureza. Trata-se, portanto, de ir além da incorporação dos avanços da ciência contemporânea simplesmente por conta da sua importância instrumental e utilitária. Do contrário, a experimentação poderá se apresentar como passe de mágica e o conhecimento como um produto acabado.

Estamos realçando que se o conhecimento, prescrito na disciplina curricular tradicional, for ensinado nas escolas num modelo tipicamente cartesiano e numa abordagem didática excessivamente conteudista e eficientista, induzirá a crença de que a ciência é neutra, objetiva e de que o seu discurso é o privilegiado na representação e controle do mundo. Esse modelo de ensino terá como consequência o esvaziamento de uma consciência crítica formadora de conceitos políticos, éticos, históricos, sociológicos e científicos diferenciados; valores educacionais necessários ao desenvolvimento da individualidade, da iniciativa de indivíduos capazes de reflexão e de ação própria, portanto, de autonomia.

Entretanto, a defesa dessa perspectiva para ação docente no ensino das Ciências na escola, não nos conduz a transformar o mesmo em uma aula de História ou Filosofia, pois, isso seria, também, empobrecedor para os alunos. Ou mesmo fazer a apologia de um ativismo pedagógico para conscientizar os alunos na lógica da ação docente do "professor alquimista"4. Todavia, o ensino não pode deixar de levar em conta uma aprendizagem mais significativa de conteúdos e significados dos 
conhecimentos científicos que contribuam para a formação integral (Bildung) do educando. É preciso educar no sentido de permiti-lo a compreender de que a ciência é um empreendimento humano falível, imbricado de interesses, consensos, dissensos e relações de poder.

Com efeito, se o conhecimento científico, prescrito no currículo escolar e desenvolvido na sala de aula, permanecer como um dogma natural, ele deixa de ser uma possível representação da realidade para se transformar em doutrina, um fim "em si mesmo", um modelo explicativo único, estático e final, portanto, em um mito. $\mathrm{E}$, como mito, induzirá e conduzirá a uma consciência ingênua que se almejava superar por meio do processo educativo.

De fato, a ciência é somente um modo possível de ver a realidade. Sendo assim, é preciso que o ensino das Ciências rompa com a lógica positivista e cientificista moderna, onde prevalece o acúmulo de informações excessivamente formais e sem relação complexa com o contexto social em que elas ocorreram. Dessa maneira, a educação para a autonomia estará se efetivando e contribuindo para uma propedêutica formação científica mais crítica e, sabidamente, mais adequada à formação da cidadania.

É inegável que se dê voz ativa ao aluno, na sala de aula, para que ele se expresse e se exponha com vista à construção de saberes que combinem com a formação humana para a participação e reflexão. Nessa perspectiva, na prática docente, a reflexão não pode ser substituída pela instrução e memorização de conteúdos conceituais fechados e não cabe à educação reproduzir, no contexto da sala de aula, uma realidade já existente nas relações sociais, dominada pelo egoísmo e pelo interesse próprio. Por certo, os alunos devem aprender a agir com discernimento, não por adesão ao dominante, mas por decisão particular, fundada no entendimento e na capacidade de serem consequentes em suas escolhas.

Tendo como foco a Bildung, é necessária, na sala de aula, uma ação docente que rompa com o fazer pelo fazer, em nome da harmonia, da ordem e da disciplina que sufoca a participação, o debate e as divergências de pontos de vista. O ensino deve fomentar a aprendizagem pautada na cooperação, tolerância e solidariedade entre os alunos e os professores. Assim, a ação docente viabilizará a autonomia do aluno em pensar e agir por conta própria e se orientará no sentido de fomentar nele a capacidade de superar o conformismo e a naturalização da 
indiferença resultante da vida social sob as relações sociais capitalistas. Esse é um dos desafios para a tarefa educativa a ser exercida pela escola.

Vale ressaltar que, se o currículo escolar das Ciências da Natureza abarcar somente o conhecimento científico à luz dos parâmetros da utilidade e da operacionalidade, numa ação docente excessivamente formal e técnica, por certo, essa prática expulsará a reflexão da sala de aula, sobretudo, do caráter histórico e transitório da produção desse conhecimento. Conforme já mencionamos, a consequência será a dogmatização dos saberes e a alienação do educando, e não sua efetiva formação. Por certo, o resultado será o que Adorno (1995) chamou de semiformação.

\section{EDUCAR É ROMPER COM A SEMIFORMAÇÃO E COM A CONSCIÊNCIA COISIFICADA}

Para Adorno, é preciso uma educação que privilegie a reflexão e que rompa com as facilidades de um raciocínio condicionado a permanecer na superfície do dado imediato. Para o pensador, quanto mais o ensino procurar se fechar ao seu condicionamento social, tanto mais a formação se converterá em mera presa da situação social existente contribuindo para educar pessoas apenas bem ajustadas. Seguindo esse ponto de vista, a organização dos currículos escolares, ao privilegiar o enfoque positivista de seriação e compartimentalização dos conhecimentos, em que esses são apresentados como imóveis e imutáveis, neutros e imparciais, sem historicidade, impedirá o avanço de um projeto emancipatório de educação que permita ao indivíduo transformar a realidade social na qual está inserido. Com efeito, se o processo educativo não pode ser abstraído do funcionamento da sociedade, desse modo, os conhecimentos ensinados na escola, não permitem serem trabalhados como se fossem objetivos, imparciais e divorciados do mundo dos valores. De fato, comprometeria uma educação para a autonomia.

Desse modo, se faz necessário escapar aos ditames de um formalismo escolar e de um ensino uniformizante cujo "pensamento enrijecido, coisificado, cuja aparente precisão de lógica discursiva nos envolve com um encantamento" (MAAR, 1995, p.14) acabando por autonomizar o conhecimento ao restringir a reflexão educacional sobre a realidade social, mascarando as relações de poder existentes. 
Nessa perspectiva, o ensino desestimula os alunos de pensar no real, com toda a sua riqueza, mutabilidade e complexidade.

$\mathrm{Na}$ semiformação, o domínio do saber, o conhecimento da cultura humana acumulada e a reflexão sobre o próprio conhecimento, são tornados e tomados como irrelevantes. Como consequência, a semiformação possibilita a adaptação e o conformismo do educando diante da realidade social, tornando-o incapaz de dúvidas. Ela aumenta o potencial de adesão sem consciência e, o resultado educacional, sugere ser a legitimação e reprodução do estabelecido. Ou seja, a difusão de uma produção simbólica na qual predomina a dimensão instrumental da razão.

Para Adorno, a semiformação é símbolo de uma consciência que renunciou à autodeterminação ao prender-se, de maneira obstinada, a elementos culturais aprovados, sem se preocupar em problematizá-los em direção à formação da personalidade emancipada. Muitas vezes por covardia, falta de coragem e, mesmo, ingenuidade.

É pertinente afirmar que Adorno, em suas críticas ao sistema escolar alemão, mostra-se radicalmente contrário a uma ação didática que desenvolva a coisificação da consciência e "a modelagem das pessoas ao se constituir numa mera transmissão de conhecimentos, com características de coisa morta e valores absolutos" (ADORNO, 1995, p.38). Sua defesa é de um processo educacional que produza uma "consciência verdadeira", subtraída pela Indústria Cultural. Com efeito, a Indústria Cultural bloqueia com seus recursos crescentes e cada vez mais sofisticados, a experiência das pessoas.

Nessa tendência, o que importa são indivíduos adaptados ao coletivo pela adesão acrítica como se a realidade social fosse um ente harmônico, perfeito e passível de aceitação. O resultado desse processo é a perda da consciência individual que é substituída pela massificação. Para Vilela,

o que é realidade como educação, que se sedimentou, não apenas na Alemanha, é uma forma evidente, utilitarista e negativa de formação das pessoas, é resultado do processo social na sociedade concreta e é neste processo que deve ser entendida. Essa educação não passa de um falso processo de socialização que se transformou, em verdade, numa semiformação, numa generalização do espírito de alienação (VILELA, 2011, p.12). 
Assim, nos defrontamos, na escola, com a maneira pela qual a semiformação se difunde, quando ela, a escola, exige dos educandos a simples memorização de fórmulas,

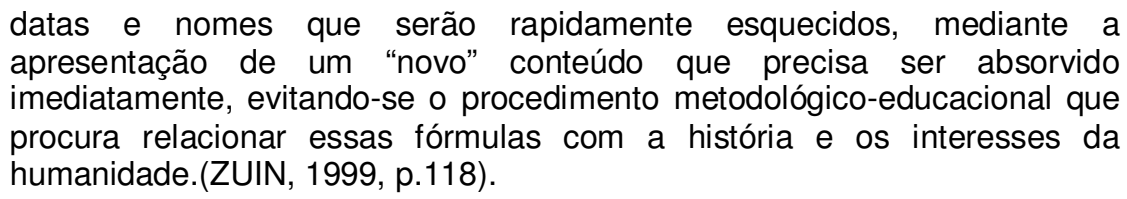
imediatamente, evitando-se o procedimento metodológico-educacional que procura relacionar essas fórmulas com a história e os interesses da humanidade.(ZUIN, 1999, p.118).

Quando o trabalho pedagógico passa a orientar-se somente para alcançar a aprovação em exames, e o diploma, transforma-se em moeda nas relações sociais mercantilizadas.

\section{A PESQUISA EMPÍRICA DA SALA DE AULA}

Pelo exposto, o trabalho procurou investigar se na sala de aula, os conhecimentos e conceitos prescritos na estrutura do currículo escolar foram ensinados, pelo docente, como uma tradução lógica, racional e natural da compreensão da realidade; se o currículo prescrito se materializou em um monumento inatacável do ponto de vista epistemológico ou em um produto sem historicidade. A linha de investigação está situada, num primeiro plano, na tradição da pesquisa da relação entre currículo proposto e currículo realizado. Mas, uma segunda perspectiva caracterizou essa pesquisa: a procura de desvendar a relação entre o currículo materializado na sala de aula e o processo pedagógico implícito na sala de aula. Interessou-nos, sobretudo desvendar e explicar como ocorreu o processo de efetivação dos conteúdos/conhecimentos e como os alunos e os professores lidaram, na sala de aula, com eles. Uma questão pontual foi pesquisar como os saberes curriculares estiveram estruturados e como foram ensinados na sala de aula. Pretendeu-se, assim, discutir o papel social da escola na realização da formação integral (Bildung) dos alunos com vista a esclarecer e a compreender o currículo materializado e mediado pela ação docente. Desse modo, quais foram as tensões e as possibilidades da realização do processo pedagógico estabelecido no currículo?

Para tanto, a sala de aula foi o foco e o "lócus" da nossa investigação, pois, ela é o lugar, onde o docente e a sua ação dão materialidade às relações existentes entre a escola e a sociedade; onde as dimensões didatização e formação 
que, dialeticamente operam o processo pedagógico, devem se espelhar na relação dos professores e alunos com o conhecimento. A lida com o conhecimento é condição para que o processo educacional seja instaurado dentro da escola. Portanto, conhecer o que se passou dentro da sala de aula foi condição para buscar nosso conhecimento sobre os sentidos da escola, revelados em cada processo pedagógico instaurado pelas disciplinas curriculares. Segundo Vilela,

\begin{abstract}
a sala de aula como o "lócus" onde o professor e sua ação revelam as relações existentes entre a escola e a sociedade, coloca-se em foco a didática do professor, sua competência e formas de lidar com o conteúdo e com as situações particulares e coletivas dos sujeitos-alunos. Aí se revela como se concretiza os currículos preestabelecidos e, portanto, como eles definem os processos de escolarização, os quais, por sua vez, revelam as possibilidades e limites de concretização, na escola e através dela, das aspirações da própria educação (VILELA, 2008, p.87.)
\end{abstract}

Assim, buscou-se pensar a escola, revelando a dialética entre o ensino idealizado e o realizado na sala de aula, procurando desvendar o que foi a aula ao abarcá-la como objeto de análise. Dessa forma, pudemos chegar à sua compreensão final apenas após o descerramento dos seus muitos elementos aparentemente ocultos que foram revelados na pesquisa de campo e nas análises. Parafraseando Adorno(2009) na Dialética Negativa, o cofre se abriu após a descoberta do segredo da fechadura. Desvelar, revelar, desvendar e contrastar a sala de aula real, com o que ela aparenta ser, dissecando o percurso entre o currículo proposto e o currículo real é o que a pesquisa se propôs.

O processo de pesquisa empírica das aulas começou no ano de 2011, por meio da coleta de dados, em uma escola particular de Belo Horizonte. As aulas foram gravadas e transformadas em protocolos de análise, segundo as normas e as regras da metodologia adotada. Os protocolos de análise foram depurados por programas de áudio, em computadores, buscando-se evidenciar a fidedignidade do que foi captado nas gravações. Para a gravação das aulas foram utilizados gravadores digitais portáteis tecnologicamente mais avançados, adquiridos pelo grupo de pesquisa. Nesta condição, o professor regente da turma não precisou ficar com o microfone fixado a sua roupa, fato que, em muitas situações de pesquisa, Ihe trazia desconforto.

Ao todo, foram gravadas 08 aulas de Física com duração média de 50 minutos cada uma das aulas. O que no final gerou 400 minutos de gravação em 
áudio. Dessas 08 aulas gravadas, 04 foram transcritas, num total médio de 14 páginas, cada transcrição. Das 04 aulas transcritas, obteve-se, em média, 220 minutos de análises, num total de 40 páginas. Ressalte-se, também, que as anotações do caderno de campo foram importantes para elucidar toda e qualquer situação duvidosa que, porventura, apareceu no momento das análises, com vista a se alcançar um estudo cientificamente válido sobre a cena da aula.

No caderno de campo, relacionou-se a matéria, a turma, o nível, o turno e o horário, o conteúdo ministrado, o nome da aula/título, a cena da aula, a organização do espaço, a composição e a distribuição dos alunos, a duração prevista e o tempo efetivo da aula, com objetivo de captar detalhes que não aparecem na gravação. Esse registro tem função de auxiliar e complementar a gravação. Nele, tendo em vista a fidedignidade da cena da aula, foram registradas as informações passíveis de não serem gravadas e que, durante a transcrição e a análise, foram importantes para desvendar as situações não audíveis, tais como o modo pelo qual o professor entrou na sala, o modo como começou a aula, o que e como os alunos responderam às várias situações da aula. Além disso, foram registradas situações da comunicação não verbal como: risos, resmungos, batidas na mesa, pausas do professor, atrasos, tosses, entre outras.

Para a transcrição da gravação, foi produzida uma legenda de situações que aparecem nas gravações, a fim de melhor elucidar o que ocorre na sala de aula. A identificação codificada dos falantes teve a finalidade de preservar as pessoas, o que é uma das condições impostas pelo método e que, também, atende a um dos preceitos do Comitê de Ética que autorizou a pesquisa. Ademais, cada aula foi cronometrada.

No protocolo, está registrado o tempo de cada aula, tendo em vista verificar como ela foi conduzida. Esse registro foi importante para a interpretação da aula, porque permitiu aferir a relação entre o tipo de atividade desenvolvida pelo professor e o tempo utilizado, situação que pôde indicar importância de uma atividade, ou até perda de tempo com tarefas.

Produzido o protocolo, ele foi revisto para se observar se tudo o que foi gravado estava registrado de forma precisa. Ademais, foi realizada uma revisão entre a aula gravada em áudio e o texto escrito (protocolo), com finalidade de checar o rigor, a procedência e a fidedignidade de toda e qualquer informação ali contida. Para tanto, foram utilizados programas de computadores mais sofisticados que 
permitiram uma maior compreensão da cena da aula. Por diversas vezes a gravação foi repetida com vista a dirimir quaisquer dúvidas em relação ao que foi gravado. Realizados esses procedimentos, os protocolos foram analisados pelo grupo de pesquisa.

Cabe ressaltar que, a presença de um especialista da área de Física, no grupo de pesquisa, foi condição fundamental para a análise. Assim, durante as análises, cada participante do grupo de pesquisa externou sua interpretação da aula, na tentativa de explicar a cena da aula.

É importante ressaltar que a análise dos protocolos ocorreu de forma horizontal, ou seja, a aula transcrita foi objeto de interpretação do início ao fim, de acordo com os passos da metodologia. A equipe de intérpretes procurou, na análise do texto coletado nas gravações (os protocolos), elucidar o que nele esteve registrado e o que o registro revelou sobre os sentidos da aula ali instaurados. Buscou-se analisar e confrontar a constante tensão inerente ao processo pedagógico, para melhor compreendê-lo.

Encerrados os trabalhos das análises dos protocolos, o pesquisador, de posse das análises, passou para a etapa de discussão das questões pontuais de sua pesquisa. Assim, foi nessa etapa da pesquisa da sala de aula que se evidenciou a autoria do trabalho a ser apresentado, porque ele foi o resultado da discussão sistematizada do pesquisador e, não somente a do grupo.

\section{A METODOLOGIA}

A abordagem dos protocolos de aulas foi qualitativa e adotou-se como procedimento metodológico empírico a "Hermenêutica Objetiva" (H.O). Essa metodologia é uma variante de pesquisa sociológica qualitativa interpretativa desenvolvida por Ulrich Oevermann da Universidade de Frankfurt e está vinculada, essencialmente, à Teoria Crítica de Theodor Adorno, isso porque há outras referências para a metodologia. O método busca reconstruir os processos interativos que produzem o sentido prático ou a construção social da realidade. Nesse sentido, o método operou de forma reconstrutiva para fazer emergir as estruturas latentes, objetivando-as. Nessa reconstrução das estruturas, o pesquisador partiu da singularidade de análises concretas de pequenas partes, buscando apreender a manifestação radical na particularidade do objeto estudado com vista ao 
entendimento do todo analisado. Quanto mais se avançou na análise sequencial de uma realidade singular da aula, por exemplo, mais se explicou o contexto interno de reprodução de sua estrutura.

Assim, a Hermenêutica Objetiva foi o procedimento de pesquisa qualitativa e interpretativa que realizou a análise hermenêutica de textos com a pretensão de encontrar a validade da interpretação. Os textos escritos que apresentam fidedignamente a situação captada em pesquisa de campo são chamados de "protocolos". Eles registram os dados coletados para a pesquisa. Assim, é importante que o texto transcrito seja um protocolo de análise, onde esteja nele enunciado, de forma clara e precisa, tudo o que foi falado e como foi falado, na sala de aula, já que o protocolo constitui-se em material essencial de análise. Feito o protocolo, ele é revisto para se observar se tudo o que foi gravado está registrado de forma precisa. Ademais, se realizou uma revisão entre a aula gravada em áudio e o texto escrito (protocolo), com finalidade de checar o rigor, a procedência e a fidedignidade de toda e qualquer informação ali contida.

Assim, a base da condução metodológica foi a análise de textos, a reconstrução dos dados, segundo a lógica da ciência hermenêutica, visando desvendar suas estruturas características e as que operaram por detrás de sua aparência. Não se tratando, portanto, de grupos focais.

A validade da análise, desenvolvida pelo método, foi garantida através da observação rigorosa dos princípios ou normas da interpretação hermenêutica objetiva. Desse modo, as regras metodológicas foram decisivas para a validade da interpretação e elaboração de resultados objetivos sobre o objeto estudado.

Um dos princípios diz respeito à forma de conceber a relação sujeito e objeto. Segundo Oevermann, o pesquisador deve ter o controle da sua subjetividade ao procurar se afastar de uma análise do objeto sustentada na projeção, esta entendida como uma interpretação do sujeito de forma espontânea e imediata. Ele não deve cair a priori sob o objeto de pesquisa numa síntese arbitrária classificatória porque essa forma de proceder torna-se ideologia; por sua vez, a identificação do pesquisador com o objeto torna-se idealização. Em relação às regras do método, tem-se: independência do contexto, literalidade, sequencialidade, substancialidade da informação e parcimônia. Vejamos cada uma delas.

A primeira regra refere-se à independência do contexto (Kontextfreiheit: Kein Rückgriff auf Vorannahmen). Nesse procedimento, a interpretação deve ater-se 
ao registrado no protocolo e pressupõe uma interpretação sequencial do texto, ou seja, de segmento em segmento. É o texto escrito que deve revelar o sentido da situação analisada. O que equivale dizer que, nesse momento da análise, o pesquisador deve desconsiderar tanto as informações do contexto quanto as informações genéricas, não podendo explicar situações registradas no protocolo que está sendo analisado com esclarecimentos buscados no contexto, ou seja, não se podem introduzir informações anteriores sobre a situação analisada. Apenas o texto escrito deve revelar o sentido da situação analisada. Cada interpretação deve e somente pode ser validada no próprio texto. Cada passagem do texto deve ser esclarecida com a pergunta: o que está explicitado aqui? (isso é, nesse registro, da forma em que se encontra). A confirmação da situação está na estrutura da situação e a sequência da análise vai demonstrar essa estrutura. Com isso não se quer dizer que o contexto não seja importante para o entendimento da situação analisada, mas apenas que ele não é apropriado naquele momento da pesquisa.

A segunda regra diz respeito à literalidade (Wörtlichekeit): o pesquisador deve decifrar o que está rigorosamente escrito e não tentar desvendar o que foi pensado pelos sujeitos da ação que estão em análise. O que está escrito foi expresso numa relação social, numa situação e tem um sentido ter sido expressado daquela forma. O registro revela o que ocorreu e, por essa razão, o texto deve ser interpretado desde a primeira palavra registrada, cada frase, do começo ao fim. $O$ intérprete não pode fazer projeções na análise do texto escrito. A interpretação literal do texto deve tomar como análise tão somente o que está escrito e não suposições teóricas, retiradas muitas vezes dos contextos sociais.

A terceira regra constitui-se no que chamamos de sequencialidade (Sequenzialität): essa é uma dimensão interna do método. Na verdade, a primeira regra, pois todas as demais são processadas na condução da análise sequencial. Os protocolos de aulas da pesquisa empírica devem ser analisados e interpretados desde a primeira palavra registrada, cada frase, do começo ao fim. Considera-se que cada palavra inicial é definidora do se segue e cada palavra final é definidora, o que se inicia após ela. $\mathrm{Na}$ análise, é importante considerar os detalhes porque eles podem revelar aspectos importantes na reconstrução do fato analisado. A reconstrução do fato está ancorada na possibilidade de acompanhamento da cadeia das informações que estão registradas; essa cadeia revela as ligações, os sentidos do que foi ali selecionado. 
A quarta regra diz respeito à substancialidade da informação (Extensivität). De acordo com essa regra, é necessário considerar todos os elementos, todas as leituras possíveis do que está registrado, de forma pragmática. Para isso, torna-se necessária a formulação de afirmativas hipotéticas, buscando a compreensão dos dados a partir das múltiplas visões e explicações de cada membro da equipe acerca do que foi registrado. A interpretação procurou responder a um sentido lógico, como cada situação registrada faz sentido dentro da situação, como se liga frases e situações anteriores do registro, o que é possibilitado pela equipe de profissionais de várias áreas do conhecimento para análise dos dados. O que se procura não é o consenso entre as diferentes explicações hipotéticas, mas a explicação mais plausível pela equipe de intérpretes. Assim, uma das interpretações deve ser escolhida pela sua indicação de maior comprovação no texto.

A quinta regra refere-se à parcimônia - regra do poupar (Sparsamkeit). Nesse sentido, deve-se realizar a análise a partir de fatos dos dados coletados, evitando-se incluir ou imaginar situações que ali não estão expressas, o que possibilitará uma leitura da realidade de forma objetiva, rigorosa e fidedigna. Ou seja, deve-se renunciar ao fictício, considerações exóticas, ao improvável; não podem ser acrescentadas informações ao que está registrado. Além disso, existe a necessidade de paciência e parcimônia na condução da interpretação. Esses cuidados impedem conclusões apressadas e interpretações infundadas. Nesse sentido, afirmações quando ausentes no texto, não constituem objeto de interpretação hermenêutica.

Seguindo esses procedimentos de análise interpretativa, o pesquisador terá condições de chegar ao conhecimento sobre o objeto que está sendo investigado, revelando sua realidade. Assim, nesse trabalho, o sentido de revelar esteve relacionado à superação da dimensão descritiva do fenômeno.

\section{APONTAMENTOS CONCLUSIVOS}

À guisa das conclusão, feito o percurso de tensionar o aparente e o real, os estudos críticos e as análises empíricas da sala de aula evidenciaram que o ensino da Física não esteve voltado para a formação de um cidadão contemporâneo, crítico e capaz de transformar o conhecimento adquirido em uma ferramenta a mais para a sua forma de pensar e de agir. Portanto, em uma 
educação voltada para a edificação da autonomia do aluno (Bildung), tal qual pensada por Adorno na crítica que ele fez à escola.

Após o contraste das sínteses elaboradas para cada uma das aulas, foram demarcadas algumas características indicadoras de uma situação da escola. Entre elas, está a ausência no cumprimento das propostas das diretrizes curriculares, haja vista que a condução didática foi excessivamente formalista, pragmática, voltada para os exames de vestibulares, para as exigências do mercado e calcada na mera transmissão de conhecimentos.

Pode-se afirmar que o ensino revelado pela pesquisa empírica da sala de aula não movimentou o espírito do aluno. Ou seja, as relações pedagógicas estabelecidas, na aula, durante o processo de didatização do conhecimento, não garantiram a efetivação da Bildung porque os alunos não se sentiram desafiados a buscarem aprender cada vez mais; condição para o pensamento autônomo e, portanto, para o exercício pedagógico de reflexão e de questionamento, imprescindíveis à formação integral.

A pesquisa demonstrou que houve negação aos alunos da crítica com relação à função social da própria ciência. Em algumas aulas analisadas o docente, ao consolidar uma visão natural do desenvolvimento científico e ao apresentar as teorias científicas como sendo resultados de mentes brilhantes dos cientistas e não como construções e possibilidades de explicações e interpretações da realidade, acabou por ratificar na sala de aula a supressão do pensamento crítico.

Se para a área de Ciências da Natureza um dos objetivos é o desenvolvimento de conhecimentos práticos e contextualizados que respondam às necessidades da vida contemporânea, visando ao exercício da cidadania, a constatação é a de que essa dimensão não apareceu nas aulas analisadas, pois o que prevaleceu foi uma ação docente impregnada de exposições conceituais, voltadas tão somente à instrução, reprodução e "decoreba" de conceitos e fórmulas. Nessa perspectiva, o domínio do saber e a reflexão sobre o próprio conhecimento, foram irrelevantes. Situação pedagógica que corroborou para a adaptação e o conformismo do educando diante da realidade social porque uma educação voltada para a formação integral (Bildung) somente se consolida a partir da construção significativa da relação do conhecimento com a realidade na qual o discurso científico revela-se, enquanto representação sobre o real, sem, no entanto, se confundir com ele. 
Tal constatação revelou ainda que não se verificou uma sistematização de ensino contextualizado e um trabalho educativo capaz de direcionar o aluno na construção do conhecimento articulado a sua vivência.

Em diversas cenas das aulas, o processo educativo foi conduzido de tal forma que a indisciplina tomou conta do ambiente educativo sem que o professor fizesse interferência alguma. Na perspectiva pedagógica kantiana, o respeito às normas de conduta são necessárias à aprendizagem. Assim, o aprender a pensar requer autoridade (não autoritarismo) no processo educativo e o professor não pode se omitir em exercer sua função na condução desse processo.

Os estudos da sala de aula revelaram ainda que, muitas vezes, prevaleceu na sala de aula a banalização do conhecimento, a circulação de conhecimentos baseados no senso comum e em informações equivocadas. Houve aulas em que estiveram presentes meias verdades e discursos ideológicos sem oportunidade de discussão por parte da turma.

Nas aulas analisadas predominou o "discurso do professor" sobre o conteúdo. Muitas das ações docentes condicionaram os alunos à passividade na aquisição do conhecimento. Assim, foi surpreendente e, tem sido, como nas aulas, contrariando a literatura de que o processo de ensino e aprendizagem atual tem natureza de ser centrado no aluno e no trabalho colaborativo, em contraposição à escola tradicional baseada no ensino do professor, o que predominou foi uma configuração de aula confinada à linguagem do professor, permeada de anacolutos ${ }^{5}$ e analogias ${ }^{6}$ não desejáveis.

Revelou-se ainda que o início das aulas, na grande maioria, foi impessoal, brusco e sem cortesia. O professor sequer cumprimenta os alunos ou vice-versa.

Durante as aulas ficou evidente que houve perda de tempo ou negação do tempolaula. Há aulas transcritas nas quais, num longo espaço de tempo (pode chegar a 30 minutos) não é possível sequer saber sobre o tema ou assunto que foi trabalhado.

Enfim, paradoxalmente, o que tem ficado evidente nas aulas analisadas é que por mais confusas que elas sejam, tem se quebrado o mito de que os alunos não têm interesse pela escola. Em muitas aulas os alunos contestam o professor, fazem perguntas e mostram interesse em aprender.

Finalmente, os resultados da pesquisa apontaram que a escola revelada, nas análises de salas de aula, não correspondeu de forma positiva a sua função de 
conduzir os alunos ao desenvolvimento de suas habilidades básicas de aprendizagem com vista a alcançarem a plena condição do exercício da cidadania e da autonomia (Bildung). No lugar da discussão, do desafio e da curiosidade, imperou a rotina e a monotonia nas tarefas. E, a forma com que os professores tem desenvolvido os conteúdos \ conhecimentos explicitou as dificuldades deles em assumirem sua função de mediadores do processo ensino-aprendizagem.

Ressalta-se que nas pesquisas de sala de aula, abarcamos escolas estaduais, municipais e particulares. E, podemos enfatizar que não se manifestaram particularidades das situações das aulas nessas diferentes escolas. As questões arroladas, da sala de aula, foram comuns a todas elas.

\section{REFERÊNCIAS}

ADORNO, T. W. Dialética negativa. Tradução Marco Antônio Casanova. Rio de Janeiro: Jorge Zahar, 2009.

ADORNO, Theodor W. Educação e emancipação. Tradução Wolfgang Leo Maar. Rio de Janeiro: Paz e Terra, 1995.

BRASIL. Parâmetros Curriculares Nacionais. Brasília, Parte III. Ciências da Natureza, Matemática e suas Tecnologias. SEMTEC/MEC. Disponível em: < http://portal.mec.gov.br/seb/arquivos/pdf/ciencian.pdf > 1998. Acesso em: 06\mai. $\backslash 2013$.

DOLL JR, William E. Currículo: uma perspectiva pós-moderna. Porto Alegre: Artmed, 2002.

MAAR, Wolfgang Leo. Á guisa de introdução: Adorno e a experiência formativa. Rio de Janeiro: Paz e Terra, 1995.

MOREIRA, Antônio Flávio B.; SILVA, Tomaz Tadeu (Org.). Currículo, cultura e sociedade. 9. ed. São Paulo: Cortez, 2006.

SILVA, Tomaz Tadeu. Documentos de identidade: uma introdução às teorias do currículo. 2. ed. Belo Horizonte: Autêntica, 1999.

VILELA, Rita Amélia Teixeira; NOACK, Juliane. A pesquisa sociológica hermenêutica objetiva: novas perspectivas para a análise da realidade educacional e de práticas pedagógicas. Caxambu, 2008. 
Disponível em:

<http://seer.bce.unb.br/index.php/linhascriticas/article/download/.../2625> Acesso

em: 30\nov. 12012 .

VILELA, Rita Amélia Teixeira. Sociedade, subjetividade e educação: perspectiva marxista e frankfurtiana. Campinas, SP: Editora Alínea, 2011. 225 p.

ZUIN, Antônio Álvaro Soares. Indústria cultural e educação: o novo canto da sereia. Campinas, SP: Autores Associados, 1999.

1 freitasg@uol.com.br - Mestre em Educação pela PUC Minas e professor de História das Revoluções nas Faculdades Arnaldo Janssen no curso de Direito.

2 eroriz@uol.com.br - Mestre em Educação pela PUC Minas e doutoranda em Educação - PUC Minas. Professora e proprietária do CEER em Belo Horizonte.

${ }^{3}$ rivilela@uol.com.br - PhD em Educação pela Universidade de Frankfurt. Professora da PUC Minas.

${ }^{4}$ Discussão apresentada na $35^{\text {a }}$ Reunião Anual da Associação Nacional de Pós-Graduação e Pesquisa em Educação do ano de 2013 (ANPEd). Nessa perspectiva, a ação educativa do professor se restringiria a um discurso que milita de maneira indiscriminada contra tudo que, de alguma forma, poderia "alienar" o aluno. Recairia sobre o professor a pretensiosa e vã ilusão de dar conta do compromisso exclusivo de conduzir a "transmutação" dos sujeitos do estado alienado ao emancipado.

${ }^{5}$ Figura de linguagem que consiste na quebra da estrutura sintática da oração. Segundo Douglas Tufano, o tipo de anacoluto mais comum é aquele em que um determinado vocábulo parece que vai ser o sujeito da oração, mas de repente a construção frasal se modifica e ele acaba sem função sintática.

${ }^{6}$ Em trabalho apresentado no Encontro de Pesquisa da Região Sudeste, em 2011, apontou que o uso de analogia em da sala de aula, como estratégia didática, exige cuidados para que os conceitos não desejáveis do análogo passem para o que ser quer ensinar. Assim, é necessário que o professor disponha de estratégias para ensinar com analogias, sem correr o risco de deixá-las incompletas ou desestruturadas. Algumas cenas da aula sugerem revelar exatamente essa situação.

RECEBIDO EM: junho/2013

APROVADO EM: julho/2013 